\title{
Memórias perdidas, identidades sem cidadania
}

Lost Memories, Identities without Citizenship

Mémoires perdues, identités sans citoyenneté

\section{Ungulani Ba Ka Khosa}

\section{(2) OpenEdition}

\section{Journals}

Edição electrónica

URL: http://journals.openedition.org/rccs/5911

DOI: $10.4000 /$ rccs.5911

ISSN: 2182-7435

\section{Editora}

Centro de Estudos Sociais da Universidade de Coimbra

Edição impressa

Data de publição: 1 Maio 2015

Paginação: 127-132

ISSN: 0254-1106

Refêrencia eletrónica

Ungulani Ba Ka Khosa, « Memórias perdidas, identidades sem cidadania », Revista Crítica de Ciências Sociais [Online], 106 | 2015, colocado online no dia 28 abril 2015, criado a 19 abril 2019. URL : http:// journals.openedition.org/rccs/5911; DOI : 10.4000/rccs.5911 


\section{UNGULANI BA KA KHOSA}

\section{Memórias perdidas, identidades sem cidadania}

Este texto procura contribuir para o debate sobre as políticas identitárias no Moçambique contemporâneo. Contrapondo, através de vários exemplos, a diversidade identitária do tecido social do país à altivez ignorante das estruturas de poder nele presentes, o texto procura problematizar, em vários momentos históricos, a fratura cognitiva entre o projeto político nacional, conceptualizado a partir das elites que controlam o Estado, e o plurilinguismo e a polifonia que constroem o tecido social real. A partir desta dicotomia o texto explora o discurso sobre a nação a várias vozes, problematizando os sentidos das lições da história de Moçambique e os múltiplos silenciamentos que a narrativa histórica dominante vem realizando.

Palavras-chave: história; identidade; memória; Moçambique; silenciamento.

Permitam-me que conte um episódio que, para muitos, ao tempo da história, terá parecido ridículo, inusitado, extemporâneo, pois aos olhos do tempo o momento era de reassentamento da população deslocada pela guerra que assolou Moçambique em mais de dez anos. A história passou-se com uma brigada do Alto Comissariado para os Refugiados das Nações Unidas, algures numa região do sul de Moçambique. A brigada, transportando centenas de camponeses, viu-se, durante mais de catorze horas, completamente desorientada ao não encontrar o lugar real de reassentamento, porque a população não atinava com os marcos que identificavam o espaço, como seja a árvore, o cemitério, o bosque.

O espaço de preservação da memória destas populações havia-se eclipsado com a guerra. No lugar do bosque, da árvore ou do cemitério familiar, encontraram a natureza no seu estado selvagem, indomesticada. Para os funcionários do Alto Comissariado das Nações Unidas para os Refugiados, na maioria moçambicanos contratados, a história entrou no anedotário local. Para eles, a reivindicação do espaço identitário da população não tinha sentido em presença da terra e da distribuição de panelas, mantas e instrumentos de produção. $\mathrm{O}$ importante estava em garantir à população os bens materiais essenciais à retoma da vida. Não lhes importava os 
referentes perdidos, os esteios à perenidade da memória. Este desencontro, desconhecimento, distanciamento, e o mais angustiante, desprezo para com a realidade identitária de parte considerável do tecido social do país, patente nos funcionários, estendia-se, a diferentes amplitudes, a toda a classe administrativa do país e, mais grave ainda, ao poder político que se apressava a dar substância à separação e interdependência de poderes consagrados na nova Constituição que proclamava os direitos, garantias e liberdades individuais.

Apercebi-me, nesse momento de euforia, de encantamento com a paz, de deslumbramento com a conquista das liberdades individuais, que o nosso país se construía sobre os cacos de identidades esfaceladas, esquecidas, detestadas. E este assassínio, desculpem a impiedade do termo, teve a cumplicidade do poder político ao tempo da proclamação da independência.

Com a proclamação da independência esperava-se que as identidades circunscritas ao universo étnico ganhassem, no espaço soberano da pátria, a liberdade e o direito de confrontarem-se com identidades afins. O nosso país tem, segundo dados de recenseamento recente, cerca de vinte e três línguas de origem banto que veiculam todo o universo cultural de etnias afins. Sabe-se que no período colonial, por mão de igrejas protestantes, houvera um esforço de fixação escrita das línguas, permitindo uma crescente alfabetização das populações, manifesta no fácil trato com a literatura religiosa amplamente traduzida nas línguas locais. Este esforço, embora centrado ao universo étnico, numa geografia precisa, teve o impacto de fazer chegar aos dias de hoje uma literatura que porventura se teria perdido com o tempo. Acresce-se a isto, embora reduzido à militância de poucos, o esforço de missionários católicos em recolher contos e provérbios, em elaborar dicionários e gramáticas das línguas veiculares das populações. Em consequência, era de se esperar que, com o advento da independência, estas iniciativas, ilhadas ao universo étnico, tivessem cidadania plena, gozando, por conseguinte, do direito de circulação e consequente confrontação com outras realidades culturais. Esperava-se que a secular presença islâmica e indiana, reduzida a nichos culturais bem delimitados, ganhasse outra amplitude no solo pátrio, de modo a que, por exemplo, as especiarias e outros aromas, enraizados ao longo da costa, se embrenhassem pelo sertão adentro e se incrustassem no adobe das palhotas da nossa existência. Esperava-se que a língua portuguesa, língua da unidade e do desenvolvimento, partilhasse o seu espaço hegemónico na educação, na informação, nos espaços públicos e privados, com outras línguas, tal como aconteceu nos princípios do século XX, quando na reduzida cidade de Lourenço Marques havia espaço para um jornal bilingue, português/ronga, o Africano e, posteriormente, o Brado Africano, 
e um diário em língua inglesa, o Lourenço Marques Guardian. A língua portuguesa nunca saiu beliscada desse convívio multilingue. Com a independência esperava-se, enfim, que as várias identidades ganhassem cidadania e contribuíssem, na sua diversidade, para a construção do tecido identitário moçambicano. Mas tal não aconteceu.

O governo da época, sob a batuta dos heróis da gesta nacionalista, transladou o princípio reinante nas zonas libertadas de matar a tribo para construir a nação. O III Congresso da Frelimo, acontecido dois anos depois da independência, em 1977, veio legitimar a uniformização cultural e ideológica como condição única para a Unidade Nacional. Estavam criadas as condições para o esbatimento da memória local e de identidades que há muito procuravam cidadania para além do espaço étnico, graças à crescente urbanização do território.

Pergunto-me hoje se é possível aquilatar as consequências do silenciamento oficial das memórias identitárias que buscaram a luz da perenidade com a independência do país? Nunca teremos a resposta adequada. Mas os sinais de que o monolitismo decretado era um erro de consequências imprevisíveis veio em forma de relatório do Comité Central da Frelimo, em 1983, em vésperas do IV Congresso, ao fazer constar que

É grande a nossa diversidade étnica e linguística. Foram diversas as formações sociais pré-coloniais, cada uma com as suas características próprias. A dominação colonial abateu-se sobre a totalidade do nosso país, mas afectou de formas diferentes as diversas regiões de Moçambique. [...] Hoje, liberto o país, devemos lutar contra a tendência simplista de recusar a diversidade como forma de realizar a unidade. Fazer isso é considerar, erradamente, que a diversidade é um elemento negativo da criação da unidade nacional; é pensar, erradamente, que a unidade nacional significa uniformidade. (FRELIMO, 1983)

Mas o medo há muito que se havia instalado no país. As identidades que a custo sobreviveram a seculares tentativas de esmagamento, fecharam-se nos seus nichos de sobrevivência. A guerra que se disseminava pelo território fez uso destes erros infantis cometidos pelos guerrilheiros da gesta.

Moçambique não se encontrou. Devo dizer, embora existam teorias em contrário, que o papel do Estado é fundamental na libertação de iniciativas que conduzam a cidadania plena. $\mathrm{E}$ os primeiros anos de independência foram fulcrais na definição da pauta da nossa sinfonia cultural. Esmagamos as notas da diversidade, silenciamos as vozes que vinham das furnas do tempo e, movidos por pretensões ideológicas de difícil sustentação, tentamos erigir um corpo, permitam-me o empréstimo, sem $\mathrm{ADN}$, incaracterístico, 
insosso, descolorido, de voz monótona, desenraizada, totalmente à deriva. Perdemos, na euforia da libertação, a oportunidade de libertar a memória e de traçar, com inteira liberdade, o nosso destino cultural.

José Luís Cabaço, político e académico moçambicano, na sua tese de doutoramento, Moçambique: identidades, colonialismo e libertação (2007), não se aventurou ao período pós-independência, mas teve a clareza de afirmar que a

identidade, sendo sempre em processo, em permanente dialéctica com o passado e com o Outro, não se conclui e nunca assume o perfil dos modelos prescritivos. [...] Esses modelos tendem a criar um novo tipo de conflitualidade social e psicológica entre a representação da identidade nacional unitária e a vida real do cidadão, problema que se agrava nas sociedades africanas pós-coloniais pela sobrevivência da estrutura tendencialmente dualista herdada da colonização [...] (Cabaço, 2007: 426)

Até hoje, quase quatro décadas volvidas após a independência, ainda se discutem as várias formas de grafar as línguas locais. De um seminário a outro, as elites vão debulhando ideias que ficam em letra morta nos relatórios que ninguém lê. As universidades, melhor, a principal universidade pública, Eduardo Mondlane, vai ensaiando cursos que legitimam educadores das línguas de base étnica. De tempos a tempos, ouve-se falar de uma experiência em ensino nas línguas locais. Pouco ou nada é publicitado. São iniciativas a saca-rolha. E, no meu entender, estão à margem da dinâmica da sociedade que se acultura acriticamente aos valores que a globalização vai, sem freios, difundindo pelos cantos mais remotos.

As elites recusam-se, à luz do dia, a dar cidadania aos valores circunscritos às suas etnias. Outros grupos, sem identificação étnica, escusam-se a trazer à luz os valores que herdaram de gerações e gerações que se foram fixando no solo pátrio. Mas todos falamos de uma diversidade a que desconhecemos os contornos específicos.

No campo que me diz respeito, literatura, tenho acompanhado algumas perversões a que os tempos modernos me dão a assistir. Volta e meia, leio aqui e ali frases como segundo a nossa literatura oral, fazendo fé nas nossas tradições orais, socorrendo-me dos saberes transmitidos à volta da fogueira, e et cetera. Pergunto-me: essa literatura oral está sendo transmitida por quem e em que espaços? Que valores se transmitem nessa literatura? Quando falamos da tradição de que tradição falamos?

Creio que as elites culturais e políticas do meu país ainda não se encontraram quanto ao objecto ou referência dos seus espaços identitários. Sou da opinião de que só posso falar da tradição quando esta me é posta a ouvir, ler e consumir. 
Quando quero falar da minha tradição, do meu passado, tenho que me ater a valores que me estão próximos e com os quais me confronto diariamente, interpretando-os de diversos ângulos quando, a palavra é bonita, em alteridade. Mas esses valores não estão comigo. E se estão, actuam subliminarmente. O que me é dado a ver e consumir não passa de arremedos baratos e descartáveis de valores e memórias dum tecido cultural que se vai esboroando. Os nossos filhos, especificamente os da faixa urbana, geração imediata à independência, perderam por completo o contacto com as línguas maternas dos pais ou avós; as âncoras da identificação cultural circunscrevem-se, a título de exemplo, aos modismos culturais hoje em voga, como o lobolo praticado nos casamentos modernos, os ritos de iniciação na floresta do cimento, as oferendas aos espíritos em árvores tornadas sagradas nas inaugurações de edifícios públicos e outros empreendimentos de cariz económico e social, e pouco mais. Não há uma literatura difundida desses fenómenos.

Nunca houve, nestes anos de secura cultural, um esforço concertado de, ao menos, propagar, por diversos meios, a literatura recolhida em tempos, ou a que, militantemente, foi acolhida por instituições culturais. Desde a alvorada da nossa independência que os currículos escolares não fazem constar provérbios e contos que espelhem o universo cultural moçambicano. Quando falamos de tradição, de memória, de que tradição e memória falamos?

Diz-se, em provérbio macua, língua falada na região norte de Moçambique, que a cobra trepa sem ter pernas - Enowa enniwela ebi mettó. Mais a sul, entre os Tsonga, diz-se: Pessoa calma (silenciosa) é cobra - Munbu wo rbula $i$ nyoka. Há aqui duas formas distintas de assumir o símbolo cobra. Para os macuas, a cobra representa versatilidade, uma capacidade invulgar de realizar determinadas actividades. Nos tsonga, pelo contrário, a cobra simboliza periculosidade; ela é o símbolo da falta de transparência, da astúcia, dos jogos de bastidores. Estes exemplos demonstram a diversidade cultural existente no meu país que não se reflecte na escola, símbolo da cidadania. As pessoas falam da tradição, mas pouco ou nada dela sabem. E o tempo vai aniquilando esses valores a que as elites se recusam a dar cidadania plena.

Várias explicações têm vindo à tona para este alheamento às realidades culturais locais. Em muitos há o medo de se perder o chão da moçambicanidade, pois temem que ao se falar da tradição, se esteja a falar da pretização das instituições, da balcanização de um país que se pauta pelo princípio da universalidade e igualdade inscrita nos direitos, deveres e liberdades fundamentais, consagrados na Constituição. Para este grupo, falar da tradição é um retrocesso, um nacionalismo redutor. Para outros, com desmedidos apetites políticos, a tradição, os valores de uma etnia, são um passaporte válido para 
a cidadania política, para uma carreira sem aferição de qualidade. E para muitos, a tradição não passa de um espaço arqueológico não catalogado. E todos, o que é triste, sejam grupos étnicos ou outros espaços identitários que secularmente se sedimentaram no país, não vêem a tradição como espaço de memória interpretando-se continuamente face a outras memórias em plena cidadania. E esta cidadania é conquistada hoje, na escrita, na televisão, na rádio, nas campanhas de saúde pública, nos intérpretes com direito igual aos de outras línguas soberanas que campeiam em salas repletas de auriculares, enfim, em todos os cantos e recantos.

A cidadania que se quer às diversas identidades ou tradições é a de abertura desses espaços a outros valores próximos e distantes. Tem-se dito, e eu perfilho, que é na troca dos paladares, dos valores culinários, que a diversidade cultural ganha o primeiro grande patamar de convívio são. Se a saudosa Natália Correia dizia que a poesia é para se comer, direi que as identidades devem ser degustadas até ao tutano, para que a diversidade cultural não seja de facto um tigre de papel neste mundo globalizado.

\section{Referências bibliográficas}

Cabaço, José Luís (2007), Moçambique: identidades, colonialismo, libertação. Tese de Doutoramento apresentada à Faculdade de Filosofia, Letras e Ciências Humanas da Universidade de São Paulo, São Paulo, Brasil.

FRELIMO (1983), Relatório do Comité Central ao IV Congresso. Colecção $4 .{ }^{\circ}$ Congresso. Maputo: Imprensa Nacional.

Artigo recebido a 11.09.2014

Aprovado para publicação a 15.01.2015

\section{Ungulani Ba Ka Khosa}

Escritor e director do Instituto Nacional do Livro e do Disco

Av. Ho Chi Min $11351^{\circ}$, Maputo - Moçambique

Contacto: ungulani@gmail.com 